\title{
Estimates of genetic parameters for stayability and their associations with traits of economic interest in Gir dairy cows
}

\author{
R.M.O. Silva ${ }^{1,2}$, A.A. Boligon ${ }^{2}$, A.R. Fernandes ${ }^{3}$, A.E. Vercesi Filho ${ }^{4}$, L. El Faro ${ }^{4}$, \\ H. Tonhati ${ }^{2}$, L.G. Albuquerque ${ }^{2}$ and A.B. Fraga ${ }^{1}$ \\ ${ }^{1}$ Centro de Ciências Agrárias, Universidade Federal de Alagoas, Rio Largo, AL, Brasil \\ 2Departamento de Zootecnia, Universidade Estadual Paulista “Júlio de Mesquita Filho", \\ Jaboticabal, SP, Brasil \\ ${ }^{3}$ Associação Brasileira de Gir Leiteiro, Uberaba, MG, Brasil \\ ${ }^{4}$ Centro de Pesquisas Bovinos de Corte, Instituto de Zootecnia, Sertãozinho, \\ SP, Brasil \\ Corresponding author: A.B. Fraga \\ E-mail: angelina.fraga@gmail.com \\ Genet. Mol. Res. 15 (1): gmr.15016958 \\ Received June 11, 2015 \\ Accepted October 23, 2015 \\ Published February 19, 2016 \\ DOI http://dx.doi.org/10.4238/gmr.15016958
}

ABSTRACT. The objective of the present study was to estimate genetic parameters for stayability at 60 months of age (STAY60) and its association with first lactation cumulative milk yield (P305), age at first calving (AFC), and first calving interval $(\mathrm{FCl})$, in order to adopt these traits as selection criteria for longevity in Gir dairy cattle. Records for 2770 cows born between 1982 and 2008 from six herds in the Brazilian states of Minas Gerais, São Paulo, and Paraíba were analyzed. The (co)variance components were estimated by a Bayesian approach using bivariate animal models. The heritability estimates were $0.37 \pm 0.09,0.23 \pm 0.04,0.26 \pm 0.06$, and $0.07 \pm 0.03$ for STAY60, P305, AFC, and FCl, respectively. The genetic correlations of STAY60 with P305, AFC, and FCl were moderate to high, with values of $0.61(0.17),-0.44(0.23)$, and $0.88(0.13)$, respectively. STAY60, P305, and AFC exhibited additive genetic variability, and these 
traits should be considered in selection indices. The indirect selection for longevity through the correlated responses of early-expression traits, such as milk production at first lactation, could be used to improve the ability of animals to remain in the herd.

Key words: Age at first calving; Genetic parameter; Longevity; First calving interval

\section{INTRODUCTION}

Zebu breeds have played an important role in dairy farming in tropical countries, particularly the Gir breed that is often used in crossbreeding schemes for milk production in Brazil and other Latin American countries. The ability of Gir cattle to adapt to the climate and large pastures, which are prevalent in tropical countries, as well as their genetic gains in recent years, has been crucial in popularizing this breed.

In dairy cattle production, longevity traits are associated with increased profit; consequently, they are an important objective of breeding programs. Various ways of assessing longevity have been reported in the literature, such as the number of days between first calving and slaughter, the number of days the cow remained lactating in the herd, survival analysis, and the ability of the cow to remain in the herd until a certain age (stayability). Stayability can be measured at any time during the life of the animal. Hudson and Van Vleck (1981) defined this trait as the ability of a cow to remain in the herd until a certain age, given the opportunity (date of birth or first calving) to remain. Age-specific stayability predictions could be useful in identifying bulls that are most likely to have daughters, and remain in production until that age (Snelling et al., 1995). It is a categorical trait, and has a value of 1 for the animal that remains in the herd until that age (success). Otherwise, a value of 0 (failure) is assigned.

According to Vollema and Groen (1996), there are two ways to include longevity in animal breeding programs: the first is direct selection by sires that were previously tested by progeny tests, and the second is indirect selection using correlated traits. For a multitrait index, the economic value of beef cattle when stayability is increased by one percent is equal to US $\$ 0.18$ (Formigoni et al., 2002). As the ability to remain in the herd is not expressed until late in the animal's life, the use of selection by progeny tests can increase the generation interval and decrease the annual genetic gain. In this case, indirect selection may occur. The selection of associated genetic traits that are expressed earlier is an alternative method of increasing the genetic gain for longevity.

This study aimed to estimate genetic parameters for stayability at 60 months of age and its association with first lactation milk yield, age at first calving (AFC), and first calving interval $(\mathrm{FCl})$, to investigate the possibility of adopting these traits as selection criteria for longevity in Gir dairy cattle.

\section{MATERIAL AND METHODS}

Data from the Brazilian Association of Gir Dairy Breeders ("Associação Brasileira de Criadores de Gir Leiteiro", ABCGIL) were used. The data included records of 2770 Gir cows that were born between 1982 and 2008 in six herds in the Brazilian states of Minas Gerais, Paraíba, and São Paulo, which were the offspring of 304 bulls and 1565 cows. The relationship matrix consisted of 6180 animals. The analyzed traits were as follows: the ability to remain in the herd 
until 60 months of age (STAY60), cumulative milk yield up to 305 days at the first lactation (P305), $\mathrm{AFC}$, and $\mathrm{FCl}$. The age of 60 months to evaluate stayability was chosen because almost $60 \%$ of all calving in the population studied occurred before this age. The means (and standard deviations) for P305, AFC, and FCl, were $2691.8 \mathrm{~kg}$ (1524 kg), 40.34 months (7.63 months), and 16.81 months (4.87 months), respectively. STAY60 was assigned a value of 1 (success) for cows that remained in the herd until 60 months, and 0 (failure) for those that were not in the herd at that age. To ensure that all of the cows had the opportunity to express STAY 60 phenotypes, females born after 2003 were excluded from the analysis for this trait. The numbers of observations for each trait were $1880,2326,2515$, and 1625 for STAY60, P305, AFC, and FCI, respectively. The numbers of animals with observations of two traits were: 1689 (STAY60 and P305), 1868 (STAY60 and AFC), and 1209 (STAY60 and FCl).

Four birth and calving seasons were included in the analysis: 1, spring (September to November); 2, summer (December to February); 3, fall (March to May); and 4, winter (June to August). The contemporary groups (CGs) were defined as farm, year, and birth season for STAY60 and $\mathrm{AFC}$. For $\mathrm{P} 305$ and $\mathrm{FCl}$, the $\mathrm{CGs}$ were defined as farm, year, and calving season. For all of the traits except STAY60, records with values above or below the range of three standard deviations from the CG mean were excluded, as well as CGs with fewer than four animals. As proposed by Harville and Mee (1984), CGs with identical STAY60 scores (i.e., groups lacking variability) were also excluded. A summary of the data (number of cows, bulls, and CGs) for each trait is shown in Table 1.

Table 1. Number of cows (No. cows), bulls (No. bulls), and contemporary groups (No. CGs) used in the study.

\begin{tabular}{l|c|c|c}
\hline Trait & No. cows & No. bulls & No. CGs \\
\hline STAY60 & 861 & 195 & 213 \\
\hline P305 & 1132 & 250 & 264 \\
\hline AFC & 1222 & 261 & 291 \\
\hline FCl & 865 & 213 & 210 \\
\hline
\end{tabular}

STAY60 = stayability at 60 months; $\mathrm{P} 305=$ milk production at first lactation; $\mathrm{AFC}=$ age at first calving; $\mathrm{FCl}=$ first calving interval.

The (co)variance components and genetic parameters were estimated by Bayesian inference, using bi-trait animal models. A nonlinear (threshold) model was applied for STAY60, and linear models were used for the other traits. Direct additive and residual genetic effects were included as random effects. Analyses were performed using THRGIBBS1F90 (Misztal et al., 2002). This software generates Markov chains for the model parameters via Gibbs sampling. In matrix notation, the general model can be represented as follows:

$$
y=X \beta+Z a+e
$$

where $y$ is the vector of observations, $\beta$ is the vector of systematic effects [CG for all traits and age at calving as a covariate (linear and quadratic effects for P305 and FCl)], $a$ is the vector of animal direct additive genetic random effects, and $e$ is the vector of unknown residual random effects. $X$ and $Z$ are the incidence matrices, and relate to systematic effects and direct additive genetic random effects, respectively. The assumptions were:

$$
\operatorname{Var}\left[\begin{array}{l}
a \\
e
\end{array}\right]=\left[\begin{array}{cc}
G \otimes A & 0 \\
0 & R \otimes I_{N}
\end{array}\right]
$$


where $G$ is the matrix of (co)variances of the direct genetic effects, $\otimes$ denotes the direct product of the matrices, $A$ is the relationship matrix, $I$ is an identity matrix, $R$ is the matrix of (co)variances of the residual effect, and $N$ is the number of animals with records.

For the systematic effects a uniform prior distribution was adopted. An inverted Wishart distribution was used for the a priori values of the direct and residual genetic (co)variances, as follows:

$$
G \mid v_{a}, V_{a} \sim I W\left(v_{a} V_{a}, v_{a}\right)
$$

(Equation 3)

and

$$
R \mid v_{e}, V_{e} \sim I W\left(v_{e} V_{e}, v_{e}\right)
$$

where $v_{\text {, and }} \mathrm{V}_{i}(i=a, e)$ are the distribution hyperparameters, which are assumed to be known. The inverted Wishart distribution is reduced to an improper uniform distribution if $u_{i}=-(k+1)$ and $V_{i}=0$ with $k=3$ (Sorensen and Gianola, 2002). The a posteriori conditional distributions of $\beta, a$, and e effects were sampled from a multivariate normal distribution. Stayability is a threshold trait; therefore, a threshold model was used, and the underlying distribution $(U)$ was determined using the following equation:

$$
U \sim N\left(X \beta+Z a, I \sigma_{e}^{2}\right)
$$

The prior distributions of the direct and residual additive genetic effects followed a multivariate normal distribution:

$$
P\left(a \mid \sigma_{a}^{2}\right) \sim N\left(0, \sigma_{a}^{2}\right)
$$

and

$$
P\left(a \mid \sigma_{e}^{2}\right) \sim N\left(0, I \sigma_{e}^{2}\right)
$$

As the variable in the underlying distribution is not observable, $\sigma_{e}^{2}=1$ is usually assumed to achieve identifiability in the likelihood function (Sorensen and Gianola, 2002). According to Gianola and Foulley (1983), after defining the model parameters the linkage between continuous and categorical scales may be set such that the probability of an observation being in the first category is proportional to the equation:

$$
P\left(y_{r}=0 \mid t, \theta\right)=P\left(U_{r}<t \mid t, \theta\right)=\phi\left(\left(t-W_{r}^{\prime} \theta\right) / \sigma_{e}\right)
$$

where $y_{r}$ is the response variable of the $\mathrm{r}^{\text {th }}$ observation with values equal to 0 or 1 if the value belongs to the first or the second category, respectively; $t$ is the threshold value, which (unless estimable) is fixed with an arbitrary value; $U_{r}$ is the value of the underlying variable for the aforementioned observation; $\phi()$ is the cumulative distribution function of a standard normal variable; $W_{r}^{\prime}$ is the vector column of incidence that links $\phi$ to the $r^{\text {th }}$ observation; and $\phi=\left(b^{\prime}, a^{\prime}\right)$ is the vector of location parameters of order s with $b$ (systematic effects) and a (random effects). 
The analysis consisted of a single chain of one million cycles with a "burn-in" of 300,000 cycles, taking a sample every 100 iterations. Therefore, 7000 samples were used to obtain the parameters. Chain convergence was assessed using procedures in R 2.9.0 (R Development Core Team, 2009), such as diagnostic convergence (Heidelberger and Welch, 1983; Geweke, 1992), and by visual examination. These procedures were performed using the Bayesian Output Analysis Program (Smith, 2005). The a posteriori estimates were obtained retrospectively using the application POSTGIBBSF90 (Misztal et al., 2002).

\section{RESULTS}

The percentage of cows that remained in the herd until the 60th month of age was $57.39 \%$. The a posteriori means, medians, and modes of the variance components and heritability estimates were similar (Table 2). The heritability estimate for STAY60, P305, AFC, FCl were $0.37 \pm 0.09,0.23$ $\pm 0.04,0.26 \pm 0.06$, and $0.07 \pm 0.03$, respectively.

Table 2. Posterior means and standard errors (SEs), modes, medians, and $95 \%$ confidence intervals $(95 \% \mathrm{Cl})$ of variance components and heritability estimates for stayability at 60 months of age (STAY60), 305 days after first lactation milk yield (P305), age at first calving (AFC), and first calving interval (FCI).

\begin{tabular}{|c|c|c|c|c|c|c|}
\hline Trait & Parameter $^{\mathrm{a}}$ & A.E. ${ }^{b}$ & Mean \pm SE & Mode & Median & $95 \% \mathrm{Cl}$ \\
\hline \multirow{3}{*}{ STAY60 } & $\sigma_{a}^{2}$ & 350 & $0.65 \pm 0.23$ & 0.58 & 0.63 & $0.07-1.57$ \\
\hline & $\sigma_{r}^{2}$ & 3499 & $1.06 \pm 0.04$ & 1.06 & 1.06 & $0.92-1.23$ \\
\hline & $h_{a}^{2}$ & 7000 & $0.37 \pm 0.09$ & 0.39 & 0.37 & $0.06-0.68$ \\
\hline \multirow{3}{*}{ P305 } & $\sigma_{a}^{2}$ & 875 & $147.2 \pm 29$ & 132.3 & 146.0 & $62-258$ \\
\hline & $\sigma_{r}^{2}$ & 1166 & $486.5 \pm 26$ & 483.0 & 486.4 & $399-567$ \\
\hline & $h_{a}^{2}$ & 7000 & $0.23 \pm 0.04$ & 0.22 & 0.23 & $0.09-0.39$ \\
\hline \multirow{3}{*}{ AFC } & $\sigma_{a}^{2}$ & 583 & $8.57 \pm 2.08$ & 8.77 & 8.57 & $2.49-17.75$ \\
\hline & $\sigma_{r}^{2}$ & 583 & $24.90 \pm 1.68$ & 24.28 & 24.90 & $17.24-29.96$ \\
\hline & $h_{a}^{2}$ & 7000 & $0.26 \pm 0.06$ & 0.25 & 0.25 & $0.07-0.51$ \\
\hline \multirow{3}{*}{$\mathrm{FCl}$} & $\sigma_{a}^{2}$ & 78 & $1.42 \pm 0.64$ & 1.01 & 1.28 & $0.25-2.97$ \\
\hline & $\sigma_{r}^{2}$ & 350 & $19.90 \pm 0.93$ & 20.04 & 19.91 & $17.62-22.93$ \\
\hline & $h_{a}^{2}$ & 7000 & $0.07 \pm 0.03$ & 0.05 & 0.06 & $0.005-0.22$ \\
\hline
\end{tabular}

${ }^{\mathrm{a}} \sigma_{a}^{2}=$ direct additive genetic variance; $\sigma_{r}^{2}=$ residual variance; $h_{a}^{2}=$ heritability. ${ }^{\mathrm{b}}$ Number of effective samples.

Genetic, phenotypic, and environmental correlation a posteriori means that were estimated for STAY60 with P305, AFC, and FCl are presented in Table 3. The genetic correlation between STAY60 and P305, STAY60 and AFC were moderate and in a favorable direction $(0.61$ and -0.44 , respectively).

The genetic correlation between STAY60 and FCl suggests that selection for improving STAY60 could result in a greater FCI. The phenotypic correlation estimated between STAY60 and P305 (0.88) indicates that animals that have high milk production at the first lactation stay longer in the herd. 
Table 3. Estimated a posteriori means and associated standard deviations (in parentheses) of genetic $\left(r_{g}\right)$, phenotypic $\left(r_{\mathrm{p}}\right)$, and environmental $\left(r_{\mathrm{e}}\right)$ correlations between the traits studied.

\begin{tabular}{l|c|c|c}
\hline & $r_{g}$ & $r_{p}$ & $r_{e}$ \\
\hline STAY60 $\times$ P305 & $0.61(0.17)$ & $0.20(0.04)$ & $0.03(0.07)$ \\
\hline STAY60 $\mathrm{AFC}$ & $-0.44(0.23)$ & $0.08(0.03)$ & $0.30(0.07)$ \\
\hline STAY60 $\mathrm{FCl}$ & $0.88(0.13)$ & $0.25(0.04)$ & $0.16(0.05)$ \\
\hline
\end{tabular}

STAY60 = stayability at 60 months of age; $\mathrm{P} 305=$ first lactation cumulative milk yield; $\mathrm{AFC}=$ age at first calving; $\mathrm{FCl}$ = first calving interval.

\section{DISCUSSION}

The heritability estimate for STAY60 shows that this trait may respond to long-term selection. However, lower estimates have been reported in studies using linear models, which are considered less suitable for the analysis of categorical data (Snelling et al., 1995; Sousa et al., 2000). Vollema and Groen (1996), using a linear model, estimated heritability that ranged from 0.01 to 0.11 for stayability at $36,48,60$, and 72 months of age in Holsteins. In the same study, these authors also studied stayability as permanence in the herd from the date of first calving, and obtained heritability estimates that ranged from 0.01 to 0.12 for stayability at $12,24,36$, and 48 months after first calving. Similarly, Forabosco et al. (2009) obtained heritability estimates that ranged from 0.02 to 0.11 for longevity in Holstein cows in 19 countries.

Comparing the heritability estimates for herd permanence obtained with different models, Marcondes et al. (2005) found that those estimated with linear models were, approximately, one third from those estimated using threshold models. In the present study, the heritability estimates were slightly larger than those reported in other studies that also used threshold models. Queiroz et al. (2007) reported heritability estimates of $0.28 \pm 0.07,0.27 \pm 0.07$, and $0.23 \pm 0.07$ for stayability at 48,60 , and 72 months, respectively, in Caracu cows. Heritability estimates of a similar magnitude to those obtained in the present study were observed for beef cattle. In Nellore cattle, a Zebu beef breed, Mercadante et al. (2000) and Van Melis et al. (2007) obtained heritability estimates that ranged from 0.22 to 0.28 for longevity and stayability, respectively.

The average heritability estimates for P305 and AFC (Table 2) indicate that such traits have reasonable additive genetic variability, and can be used as selection criteria in breeding programs. Regarding $\mathrm{FCl}$ (Table 2), the low magnitude of estimated heritability indicates that performance changes can probably be obtained by environmental improvements.

The genetic association between STAY60 and P305 suggests that daughters of bulls with high breeding values for milk production tend to have a high genetic potential to remain in the herd. Therefore, it is possible to obtain correlated gains for longevity by selection for milk yield at the first lactation. This result agrees with those reported by Hudson and Van Vleck (1981) working with Holstein cows. They found positive genetic correlations, although of moderate magnitude, between milk yield at the first lactation and stayability at $36,48,60,72$, and 84 months of age.

The genetic correlation between STAY60 and AFC (-0.44) indicated that long-term selection to decrease AFC should lead to genetic gains in the ability to stay in the herd. A strong association, also in a favorable direction (-0.63), was reported by Buzanskas et al. (2010) in the Canchim beef breed. The estimated heritability for AFC and its genetic correlation with STAY60 suggest that the inclusion of this trait in selection indices could result in genetic gains, in addition to improving longevity in Gir herds. Therefore, females that start their reproductive life early may have reduced production costs, helping to increase herd productivity. 
The positive association between STAY60 and $\mathrm{FCl}$ could be explained by the average age of the animals at first calving (16.81 months). Adding the AFC and FCl together is almost 60 months of age; however, little genetic change would be expected for $\mathrm{FCl}$ when selecting for STAY60, because the estimated heritability for $\mathrm{FCl}$ was low, indicating that the additive genetic variation represented a small proportion of the total phenotypic variance.

However, the estimate of environmental correlation between STAY60 and P305 was close to zero. The low positive phenotypic correlation obtained between STAY60 and AFC could be due to management practices, because animal weight is used as a criterion to start a female's reproductive life. Feeding is often neglected in this category of animal, which can reduce weight gain and delay the first conception. This hypothesis is also supported by the estimative of environmental correlation between these traits (Table 3), which was positive and moderate. The phenotypic association between STAY 60 and $\mathrm{FCl}$ suggests that females with high calving intervals tend to stay longer in the herd. This undesirable phenomenon is probably caused by physical and physiological stress in primiparous cows, which tends to delay re-conception and the start of the next lactation. Another possible explanation is that breeders delay conception after first calving, and expect to maintain a high lactation persistency and length. The Gir breed, as with other Zebu dairy breeds, tends to have a short first lactation length, with an average of around 280 days (Albuquerque et al., 1999; Peixoto et al., 2012). The environmental correlation between STAY60 and FCI suggests that non-genetic effects also keep females with high calving intervals longer in the herd.

Stayability measured at 60 months, milk production at first lactation, and age at first calving had low to moderate heritability estimates in Gir dairy cattle and should be considered in breeding programs. The indirect selection for longevity through correlated early-expression traits, such as milk yield at first lactation, could be used to improve the ability of animals to remain in the herd.

\section{Conflicts of interest}

The authors declare no conflict of interest.

\section{ACKNOWLEDGMENTS}

The authors thank the Brazilian Association of Gir Dairy Breeders (Associação Brasileira de Criadores de Gir Leiteiro, ABCGIL) and the farms for providing the data. Research supported by Coordenação de Aperfeiçoamento de Pessoal de Nível Superior (CAPES). Helpful comments and suggestions from the reviewer are acknowledged.

\section{REFERENCES}

Albuquerque MSM, Freitas MAR and Teodoro RL (1999). Genetic and phenotypic parameters of productivity traits on the first three lactations in Gyr cattle herds. Genet. Mol. Biol. 22: 177-181. http://dx.doi.org/10.1590/S1415-47571999000200007

Buzanskas ME, Grossi DA, Baldi F, Barrozo D, et al. (2010). Genetic associations between stayability and reproductive and growth traits in Canchim beef cattle. Livest. Sci. 132: 107-112. http://dx.doi.org/10.1016/j.livsci.2010.05.008

Forabosco F, Jakobsen JH and Fikse WF (2009). International genetic evaluation for direct longevity in dairy bulls. J. Dairy Sci. 92: 2338-2347. http://dx.doi.org/10.3168/jds.2008-1214

Formigoni IB, Silva JAIV, Brumatti RC, Ferraz JBS, et al. (2002). Economic aspects of stayability as selection criterion in beef cattle industry in Brazil. Proceedings of the 7th World Congress on Genetics Applied to Livestock Production. Montpellier, France.

Geweke J (1992). Evaluating the accuracy of sampling-based approaches to the calculation of posterior moments. In: Bayesian statistics 4 (Bernardo JM, Berger JO, Dawid AP and Smith AFM, eds.). Oxford University Press, Oxford, pp. 625-631. 
Gianola D and Foulley J (1983). Sire evaluation for ordered categorical data with a threshold model. Genet. Sel. Evol. 15: 201224. http://dx.doi.org/10.1186/1297-9686-15-2-201

Harville DA and Mee RW (1984). A mixed model procedure for analyzing ordered categorical data. Biometrics 40: $393-408$. http://dx.doi.org/10.2307/2531393

Heidelberger P and Welch PD (1983). Simulation run length control in the presence of an initial transient. Oper. Res. 31: 11091144. http://dx.doi.org/10.1287/opre.31.6.1109

Hudson GFS and Van Vleck LD (1981). Relations between production and stayability in Holstein cattle. J. Dairy Sci. 64: 22462250. http://dx.doi.org/10.3168/jds.S0022-0302(81)82836-6

Marcondes CR, Paneto JCC, Silva JAIIV, Oliveira HN, et al. (2005). Threshold versus linear model analyses in stayability for Nellore cows. Arq. Bras. Med. Vet. Zootec. 57: 234-240. http://dx.doi.org/10.1590/S0102-09352005000200016

Mercadante MEZ, Lôbo RB and Oliveira HN (2000). Estimates of (co)variances among reproductive and growth traits in female Nellore cattle. Rev. Soc. Bras. Zootec. 29: 997-1004. http://dx.doi.org/10.1590/S1516-35982000000400008

Misztal I, Tsuruta S, Strabel T, Auvray B, et al. (2002). BLUPF90 and related programs (BGF90). Proceedings of the 7th World Congress on Genetics Applied to Livestock Production, Montpellier, France.

Peixoto MGCD, Verneque RS, Santos GG, Bruneli FAT, et al. (2012). Programa nacional do Guzerá para leite: resultados do teste de progenie, do programa de melhoramento genético de zebuínos da ABCZ e do núcleo MOET, Embrapa Gado de Leite Juiz de Fora, (Documentos, 153).

Queiroz SA, Figueiredo G, Silva JAV, II, Espasandin AC, et al. (2007). Estimation of genetic parameters of stayability in Caracu cattle. Rev. Soc. Bras. Zootec 36: 1316-1323. http://dx.doi.org/10.1590/S1516-35982007000600013

R Development Core Team (2009). R: A language and environment for statistical computing. R Foundation for Statistical Computing, Vienna, Austria.

Smith BJ (2005). Bayesian Output Analysis Program (BOA) version 1.1. Available at [http://www.public-health.uiowa.edu/boa/]. Accessed June 6, 2011.

Snelling WM, Golden BL and Bourdon RM (1995). Within-herd genetic analyses of stayability of beef females. J. Anim. Sci. 73: 993-1001.

Sorensen D and Gianola D (2002). Likelihood, Bayesian, and MCMC methods in quantitative genetics. Springer-Verlag, New York.

Sousa WH, Pereira CS, Bergmann JAG, Silva FLR, et al. (2000). Estimates of components of variance and genetic parameters for reproductive traits by means of linear and threshold models (Supl. 2). Rev. Soc. Bras. Zootec. 29: 2237-2247.

Van Melis MH, Eler JP, Oliveira HN, Rosa GJ, et al. (2007). Study of stayability in Nellore cows using a threshold model. J. Anim. Sci. 85: 1780-1786. http://dx.doi.org/10.2527/jas.2005-608

Vollema AR and Groen AF (1996). Genetic parameters of longevity traits of an upgrading population of dairy cattle. J. Dairy Sci. 79: 2261-2267. http://dx.doi.org/10.3168/jds.S0022-0302(96)76603-1 